\title{
Microbial-based evaluation of foaming events in full-scale wastewater treatment plants by microscopy survey and quantitative image analysis
}

\author{
Cristiano Leal $^{1} \cdot$ António Luís Amaral ${ }^{1,2} \cdot$ Maria de Lourdes Costa $^{3}$
}

Received: 14 December 2015 / Accepted: 22 April 2016/Published online: 30 April 2016

(C) Springer-Verlag Berlin Heidelberg 2016

\begin{abstract}
Activated sludge systems are prone to be affected by foaming occurrences causing the sludge to rise in the reactor and affecting the wastewater treatment plant (WWTP) performance. Nonetheless, there is currently a knowledge gap hindering the development of foaming events prediction tools that may be fulfilled by the quantitative monitoring of AS systems biota and sludge characteristics. As such, the present study focuses on the assessment of foaming events in full-scale WWTPs, by quantitative protozoa, metazoa, filamentous bacteria, and sludge characteristics analysis, further used to enlighten the inner relationships between these parameters. In the current study, a conventional activated sludge system (CAS) and an oxidation ditch (OD) were surveyed throughout a period of 2 and 3 months, respectively, regarding their biota and sludge characteristics. The biota community was monitored by microscopic observation, and a new filamentous bacteria index was developed to quantify their occurrence. Sludge characteristics (aggregated and filamentous biomass contents and aggregate size) were determined by quantitative image analysis (QIA). The obtained data was then processed by principal components analysis (PCA), cross-correlation analysis, and decision trees to assess the foaming occurrences, and enlighten the inner
\end{abstract}

Responsible editor: Gerald Thouand

António Luís Amaral

lpamaral@isec.pt

1 Instituto Politécnico de Coimbra, ISEC, Rua Pedro Nunes, Quinta da Nora, 3030-199 Coimbra, Portugal

2 CEB - Centre of Biological Engineering, Universidade do Minho, Campus de Gualtar, 4710-057 Braga, Portugal

3 CERNAS - Center of Studies on Natural Resources, Environment and Society, Instituto Politécnico de Coimbra, ESAC, Bencanta, 3045-601 Coimbra, Portugal relationships. It was found that such events were best assessed by the combined use of the relative abundance of testate amoeba and nocardioform filamentous index, presenting a $92.9 \%$ success rate for overall foaming events, and 87.5 and $100 \%$, respectively, for persistent and mild events.

Keywords Protozoa and metazoa - Filamentous bacteria . Quantitative image analysis · Activated sludge systems . Filamentous bacteria index · Principal components analysis . Decision trees

\section{Introduction}

Activated sludge (AS) systems are constituted by living organisms, mainly bacteria and protozoa, as well as organic and inorganic compounds acting as nutrient sources. It is recognized that floc-forming bacteria, such as aerobic heterotrophic (feeding on organic matter) and autotrophic (nitrifying and sulfur oxidizing), as well as denitrifying, sulfate-reducing, and phosphate-accumulating bacteria (PAO), are the main organisms responsible for pollution reduction in AS systems (Duchène and Cotteaux 1998; Eikelboom 2000; Jenkins et al. 2003). By contrast, with the exception of a few filamentous sulfur-oxidizing species, filamentous bacteria are not considered to be the main responsible for the pollution control in well-functioning AS systems. In fact, it is known that the major role played by filamentous bacteria in these systems lays on the establishment of the microbial aggregate (flocs) structure, which is a key feature regarding the sludge characteristics. An excess, resulting in filamentous bulking or foaming events, or a shortage of filamentous bacteria, resulting in dispersed growth or pinpoint floc formation, leads to poor sludge characteristics and to problems in the reactor and secondary clarifier. Thus, an important aspect in the 
performance evaluation of an AS system is the determination of the sludge characteristics, particularly at the level of the aggregated and filamentous bacteria contents and aggregate size. Indeed, a correct balance between the floc-forming and the filamentous bacteria (forming the aggregate backbone) is of crucial importance for obtaining good sludge characteristics (Duchène and Cotteaux 1998; Eikelboom 2000; Jenkins et al. 2003).

Protozoa and metazoa organisms in AS systems mainly feed on bacteria, thus controlling bacteria population, and contributing to effluent clarification and increased final effluent quality (Ganczarczyk 1983). Within the protozoa, testate amoeba and ciliates (crawling, carnivorous, and stalked) predominate in good AS operating conditions, whereas flagellates, naked amoeba, and free-swimming ciliate prevalence may indicate reactor disturbances associated with transient phenomena, low aeration, high organic loads, and high food to microorganism (F:M) ratios (Richard 1991). On the other hand, metazoa thrive in AS systems with high sludge retention times (Pandolfi et al. 2007). In fact, it is possible to establish a close correlation between the predominance of certain taxa and several AS systems' operational parameters (Canler et al. 1999; Madoni 2004). Indeed, Madoni (1994) has already proposed the Sludge Biotic Index (SBI) to correlate protozoa and metazoa contents with the AS physicochemical and operational conditions and effluent quality. Furthermore, the usefulness of the SBI has already been demonstrated for AS system monitoring, complementing the information obtained by filamentous bacteria monitoring (Nicolau et al. 2001, 2015; Ginoris et al. 2007; Santos et al. 2015).

The formation of thick stable brown (persistent) foams, within the AS process, is a familiar operational problem causing the sludge to rise in the reactor and hindering the wastewater treatment plant (WWTP) performance (Fryer and Gray 2012). It is known that the overgrowth of filamentous bacteria such as nocardioforms (Nocardia, Gordonia), Nostocoida limicola, Type 1863, and even Microthrix parvicella is usually associated to foaming events (Duchène and Cotteaux 1998; Eikelboom 2000; Jenkins et al. 2003). It is then imperative to identify the main filamentous bacteria species present in the AS system, for an efficient foaming elimination. Furthermore, the exact mechanism of how the foaming process is initiated, and further stabilized, still remains unknown. Hence, there is a clear need to further understand, predict, and assess foaming events in full-scale WWTPs (Kocianova et al. 1992; Lemmer et al. 2000; Hladikova et al. 2002; Nakajima and Mishima 2005; Heard et al. 2008).

Currently, in AS system monitoring, solely a limited number of tools, capable of predicting the onset of foaming events, are available (Comas et al. 2008). Furthermore, the most widely used techniques for assessing the susceptibility of AS systems to withstand biological foaming events are physicochemical determinations, such as AS hydrophobicity, foam area, foaming tests (Scum Index, foam rating) (Torregrossa et al. 2005), and foam potential (Fryer et al. 2011). More recently, Fryer and Gray (2012) proposed the Foaming Scum Index, based on foam stability, coverage, suspended solid contents, and biological composition. However, there is still a knowledge gap with respect to the sludge characterization and quantitative biota determinations which may play a crucial part in effectively predicting foaming events. Such gap may be resolved by the proposed quantitative methodology for the biota and sludge characterization of AS systems.

Quantitative image analysis (QIA) has been increasingly used for wastewater system characterization, since the initial studies of Grijspeerdt and Verstraete (1997) using QIA to relate sludge characteristics to its settling ability. More recently, QIA has been used to characterize the WWTP biomass structural changes in result of different operating conditions (da Motta et al. 2001, 2003; Amaral and Ferreira 2005; Lopez et al. 2005; Jenné et al. 2007; Pandolfi et al. 2007; Pons et al. 2009). However, the large data contents provided by QIA render indispensable the use of chemometric techniques to organize the overwhelming information, such as principal components analysis (PCA), cross-correlation analysis, and decision trees. As matter of fact, chemometric techniques have already proven to be a valuable tool for the correlation of WWTP operating conditions with the sludge characteristics (Singh et al. 2005; Mesquita et al. 2008, 2011; Tharrault et al. 2009).

The main objective of this work focused on the assessment of foaming events, in full-scale WWTPs, by quantitative protozoa, metazoa, filamentous bacteria, and sludge characteristics data. Furthermore, the enlightenment of the inner relationships between these parameters was also pursued. With this aim, two different WWTPs were studied, representing two different AS systems: a conventional AS (CAS) and an oxidation ditch (OD). For that purpose, the protozoa, metazoa, and filamentous bacteria communities were monitored by microscopic observation, alongside sludge characteristics (aggregated and filamentous biomass contents and aggregate size). A new filamentous bacteria index was developed to quantify their occurrence, whereas the protozoa and metazoa quantification allowed the determination of the SBI. Sludge characterization was performed by means of QIA, whereas principal components analysis (PCA), cross-correlation analysis, and decision trees were performed to assess the foaming events and enlighten the inner relationships between the set of acquired parameters.

\section{Material and methods}

\section{Experimental survey}

The AS samples analyzed in this work were collected during the spring and summer periods from two WWTPs treating 
domestic effluents, in Coimbra district (Center of Portugal), presenting two different AS systems, namely a conventional AS (CAS WWTP) projected for 3000 equivalent inhabitants, and an oxidation ditch (OD WWTP) projected for 3800 equivalent inhabitants. In both cases, the incoming effluent was comprised of domestic wastewaters from the same area, and the incoming BOD/COD ratio was similar between the two WWTPs. The CAS WWTP consisted of three basic units: an aeration tank, where biomass grows aerobically in suspension; a secondary clarifier where the sludge settles; and a recirculation unit to return the settled sludge to the aeration tank. Regarding the OD WWTP, the biological wastewater treatment is performed by an oxidation ditch, operating in low organic loads, extended aeration, and high retention times. The sludge age was maintained roughly around 40 days.

A total of 19 samples were collected from the CAS system during the months of June and July, whereas from the OD system, 22 samples were collected during the months of May, June, and July.

\section{Analytical procedures}

The dissolved oxygen concentration (DO) was automatically controlled in both WWTPs, and throughout the monitoring period, the mixed liquor DO was maintained around $0.9 \mathrm{mg} \mathrm{O}_{2} / \mathrm{L}$ in the CAS WWTP and between 0.5 and $2.5 \mathrm{mg} \mathrm{O}_{2} / \mathrm{L}$ in the OD WWTP.

The mixed liquor suspended solids (MLSS) were determined according to APHA et al. (1998). A volume of $25 \mathrm{~mL}$ was placed in a crucible, dried in an oven at $105^{\circ} \mathrm{C}$ for $12 \mathrm{~h}$, and then placed in a desiccator to cool down to room temperature. Finally, the crucible was weighted through the use of an AG204 Metler Toledo lab scale (Metler Toledo, Greifensee, Switzerland) to determine the MLSS.

The chemical oxygen demand (COD) was determined according to Tchobanoglous et al. (2003). A sample volume of $2.5 \mathrm{~mL}$ was digested with $1.5 \mathrm{~mL}$ of a $\mathrm{K}_{2} \mathrm{Cr}_{2} \mathrm{O}_{7}$ (digestive) solution and $3.5 \mathrm{~mL}$ of an $\mathrm{Ag}_{2} \mathrm{SO}_{4} / \mathrm{H}_{2} \mathrm{SO}_{4}$ acid solution at $150{ }^{\circ} \mathrm{C}$ for $2 \mathrm{~h}$. Absorbance was further determined at $600 \mathrm{~nm}$ through the use of a UV-120-01 Shimadzu spectrophotometer (Shimadzu, Kyoto, Japan). Calibration curves with standardized potassium hydrogen phthalate (KHP) solutions were previously obtained to allow determining the COD.

The biochemical oxygen demand (BOD) was determined according to Tchobanoglous et al. (2003). A wastewater sample was placed in a $300-\mathrm{mL}$ glass bottle and diluted with a nutrients and oxygen saturated solution. The glass bottles were then incubated for 5 days at $20^{\circ} \mathrm{C}$, and the oxygen concentration was measured through the use of a WTW OxiTop system (WTW GmbH, Weilheim, Germany).

All the above physicochemical parameters were provided by the WWTP's authorities.

\section{Determination of the aggregated and filamentous biomass contents and aggregate size}

\section{Samples visualization and image acquisition}

All samples regarding the sludge characterization and biota (protozoa, metazoa, and filamentous bacteria) monitoring were collected from the same locations and depths, within the reactors, for representative reasons. Furthermore, the sample collection location was chosen away from the reactors walls and from the aeration inlets, due to the fact that these locations present different sludge characteristics than the reactor bulk. Sample visualization and image acquisition, to estimate the aggregated and filamentous biomass contents, as well as the microbial aggregate size, was performed within a maximum of $12 \mathrm{~h}$ upon sample collection at the WWTP. Dilutions were first performed with distilled water and the dilution ratios were selected as the minimum dilution allowing for the attainment of an aggregate recognition percentage (percentage of aggregates with their full area within the image borders) of $80 \%$. This procedure has been already published (Mesquita et al. 2010), with the obtained results demonstrating the feasibility of this methodology to separate enclosed and overlapping aggregates, while avoiding increasing statistical errors for higher dilution ratios. A 1:80 dilution was used for the OD WWTP samples and a 1:160 dilution for the CAS WWTP samples.

Microscopic visualization was then performed in triplicate, by depositing $100 \mu \mathrm{L}$ of the diluted samples in a slide, further heated in an oven at $50{ }^{\circ} \mathrm{C}$ for $2 \mathrm{~h}$. The employed methodology is a variation of the air dry methodologies already employed by other authors (Louvet et al. 2010; Stalder et al. 2013) for increased contrast and optimal focusing of the aggregated and filamentous bacteria image acquisition. In the present case, the use of an oven with temperature and time control increases the reproducibility of the air dry methodology. Furthermore, no sludge deflocculation was apparent by the employed dry mount procedure. All the images were acquired in a LEICA DM2000 microscope (Leica, Wetzlar, Germany), at $\times 100$ magnification, coupled to a Leica DFC310 FX camera (Leica, Wetzlar, Germany). Image acquisition was performed in $1392 \times 1038$ pixels and 8-bit format through the Leica Application Suite (LAS) software (Leica, Wetzlar, Germany). Around 120 images per sample were acquired in bright field microscopy to obtain representative information of the sludge.

\section{Image processing and analysis}

The image processing and analysis programs, for the determination of the aggregated and filamentous biomass contents and aggregate size, were developed in Matlab 7.3 (The Mathworks, Inc., Natick) language, adapting a previous 
version developed by Amaral (2003). Primarily, the image processing program determines the binary images of both the aggregated biomass and protruding filamentous bacteria, comprising the image pretreatment, segmentation, and debris elimination steps. Subsequently, the image analysis program allows the determination of the aggregate contents and size from the aggregated biomass binary image, as well as the filament contents of the filamentous biomass binary image. The total microbial aggregate projected area per volume (TA/Vol) was used as an indirect measure of the aggregated biomass contents, whereas the total filament length per volume (TL/Vol) was used as a measure of the filamentous biomass contents in the AS system. Furthermore, the total filament length per total aggregate area ratio (TL/TA) was also determined (Amaral 2003), expressing the ratio between filamentous and aggregated biomass in the AS system, and together with the above parameters can be used to diagnose sludge settling problems. In fact, these parameters have been already found helpful to assess AS system malfunctions (Mesquita et al. 2008, 2011; Costa et al. 2013) such as filamentous bulking (with large contents of filamentous bacteria, thus high TL/Vol and TL/TA values) or viscous bulking (presenting large contents of microbial aggregates, thus high TA/ Vol values). Therefore, it was expected that these parameters would also be useful in assessing foaming occurrences.

Furthermore, the microbial aggregates were divided into three size classes: microflocs below $0.025 \mathrm{~mm}$, mesoflocs between 0.025 and $0.25 \mathrm{~mm}$, and macroflocs above $0.25 \mathrm{~mm}$ in equivalent diameter. The area percentages of each aggregate class were then calculated and used to determine the predominant aggregate size class. The usefulness of this parameter has already been demonstrated in diagnosing sludge settling problems due to viscous bulking (higher macrofloc area percentages), and high mixed liquor turbidity problems due to pinpoint floc formation (higher microfloc area percentages) in AS systems (Mesquita et al. 2011). Again, it was expected that this parameter would also be useful in assessing foaming occurrences.

\section{Protozoa and metazoa monitoring}

The microscopic observation of the CAS and OD WWTPs samples, to evaluate the protozoa and metazoa communities, was performed in live samples within a maximum of $3 \mathrm{~h}$ upon sample collection at the WWTP, providing aeration. Microscopic evaluations were performed in triplicate, by depositing $25 \mu \mathrm{L}$ samples in a slide and covering it with a $20 \times 20$-mm cover slip, using bright field microscopy, at a $\times 100$ total magnification, in a LEICA DM2000 microscope (Leica, Wetzlar, Germany). This methodology was adapted from Madoni (1994) and Dubber and Gray (2009) in order to obtain good reproducibility results (probability of $58.4 \%$ of recovering all the present species except the three rarest). The identification of the different protozoa and metazoa organisms was based on morphological, locomotion patterns, and mixed liquor distribution characteristics, according to classification guides presented in Canler et al. (1999) and Madoni (2004). The main morphological characteristics determined included the size, shape, presence of flagella, cilia (including distribution), cirri, pseudopodia, theca, stalk, micro- and macronucleous (in ciliates), tentacles, and regarding the stalked protozoa the nucleus shape and location, myoneme, formation of colonies, and stalk retraction, among others. After the protozoa and metazoa organism identification, the overall contents of metazoa, naked amoeba, testate amoeba, and flagellated and ciliated protozoa were determined. Within this last group, the free-swimming, stalked, crawling, and carnivorous ciliate contents were also assessed.

From the quantification of each protozoa and metazoa organism, the relative abundance (number percentage) of the testate amoeba, stalked + crawling ciliates, free-swimming + flagellates, and metazoa was next determined. Furthermore, the Sludge Biotic Index (SBI), proposed by Madoni (1994), was also determined. The advantage of this method relies on providing a numerical value, ranging from 0 (worst operating conditions) to 10 (most favorable conditions), thus enabling the monitoring of the prevalent WWTP operating conditions on a daily basis.

\section{Filamentous bacteria monitoring}

The microscopic observation of the CAS and OD WWTPs samples to evaluate the filamentous bacteria communities was performed within a maximum of $3 \mathrm{~h}$ upon sample collection at the WWTPs. Microscopic evaluations were performed in triplicate, by depositing $25 \mu \mathrm{L}$ samples in a slide and covering it with a $20 \times 20$-mm cover slip, using phase contrast microscopy, at a $\times 1000$ total magnification, in a LEICA DM2000 microscope (Leica, Wetzlar, Germany). Gram and Neisser staining were also performed, when necessary, for identification purposes. These staining procedures allow characterizing the filamentous bacteria as Gram positive, Gram negative, or variable, and as Neisser positive or negative, and are considered an essential tool in filamentous bacteria identification. Therefore, the identification of the different filamentous bacteria organisms was based on the morphological and physiological (Gram and Neisser reactions) characteristics, according to classification guides presented in Eikelboom (2000) and Jenkins et al. (2003). The main morphological characteristics determined included the cell morphology (bacilli, rectangular, oval, disc-shaped, square, or irregular), cell diameter, cell length, branching, attached bacteria, filaments morphology (straight, smooth, bent, twisted, or irregular), sheath, septa, constrictions, characteristic inclusions, and even locomotion, among others. 
Moreover, a new filamentous bacteria index, representing the abundance of a given filamentous bacteria organism, was developed by multiplying the total filamentous bacteria contents (TL/Vol) by the relative abundance (in number percentage) in a given sample of each filamentous bacteria organism. In order to determine each filamentous bacteria relative abundance, visual inspections of the $25 \mu \mathrm{L}$ samples were performed and each filamentous bacteria was rated from 0 to 3 in the following manner: 0 if absent, 1 for 1-10 filaments $(25 \mu \mathrm{L}), 2$ for $11-20$ filaments $(25 \mu \mathrm{L})$, and 3 for $>20$ filaments $(25 \mu \mathrm{L})$. From the overall results in each sample, the filamentous bacteria relative abundance was next determined.

\section{Principal component analysis}

Principal component analysis (PCA) decomposes the data matrix $X$ as the sum of the outer product of $T$ (containing the scores) and $P$ (containing the loadings) plus a residual matrix $E$ :

$X=T P^{\prime}+E$

Each principal component (PC) captures the maximum variation not explained by the former PCs, i.e., the first PC maximizes the covariance in the original data and the subsequent PCs maximize the covariance in the residual matrices after extracting the former PCs. The dimensional reduction is based on the fact that the PCs are orthogonal, and hence uncorrelated. It should be stressed that the PCs are linear combinations of the original variables and, thus, abstract variables used to visualize latent structures and latent phenomena in the data. In this way, the original data is projected into a new coordinate system in which the objects are described by the scores and the variables by the loadings (Einax et al. 1997). In this study, Matlab 7.3 (The Mathworks, Inc. Natick) was used to perform the PCA analysis.

\section{Decision trees}

A decision tree is a predictive model based on feeding an input data matrix to a series of consecutive yes/no queries, in order to predict a predefined response vector. Each query evaluates a given condition, and, depending on the obtained answer, either proceeds to a new query or arrives at the intended response value. In order to avoid overfitting the decision tree to the input training values, the number of branches should be carefully chosen. Indeed, the decision tree lower branches can be strongly affected by outliers and other artifacts on the data set. The best tree size can be determined by cross-validation, determining a resubstitution estimate of the error variance, and a cross-validation estimate for the tree and for a series of pruned trees. Then the best tree is chosen as the one presenting the residual variance equal to one standard error above the minimum value along the cross-validation line (Breiman et al. 1984). In this study, Matlab 7.3 (The Mathworks, Inc. Natick) was used to perform the decision trees.

\section{Results and discussion}

\section{Operational parameters}

The average, minimum, maximum, and standard deviation values for the MLSS (reactor), and COD and BOD (incoming effluent), in the CAS and OD WWTPs are presented in Table 1. The COD values of the OD WWTP incoming effluent ranged from 288 to $896 \mathrm{mg} \mathrm{O}_{2} / \mathrm{L}$, throughout the monitoring period, whereas the BOD ranged from 144 to $443 \mathrm{mg} \mathrm{O}_{2} / \mathrm{L}$. The average incoming BOD/COD ratio was 0.51 , reflecting an incoming wastewater with good biodegradability properties (BOD/COD ratio close to 0.5 according to Tchobanoglous et al. 2003). Within this period, the OD WWTP presented MLSS values ranging from 2700 to $5400 \mathrm{mg} / \mathrm{L}$, and a BOD removal efficiency ranging from 97 to $99 \%$ (with an average value of $98 \%$ ), while the COD removal efficiency values ranged from 85 to $95 \%$ (with an average value of $90 \%$ ). With respect to the CAS WWTP, the $\mathrm{COD}$ in the incoming effluent ranged from 696 to $1136 \mathrm{mg} \mathrm{O} / \mathrm{L}$, whereas the BOD ranged from 396 to $543 \mathrm{mg} \mathrm{O}_{2} / \mathrm{L}$. The average incoming BOD/COD ratio was 0.51 , similar to the OD WWTP. Within this period, the CAS WWTP presented MLSS values ranging from 6190 to $9500 \mathrm{mg} / \mathrm{L}$, and a BOD removal efficiency ranging from 94 to $97 \%$ (with an average value of $95.5 \%$ ), while the COD removal efficiency values ranged from 84 to $94 \%$ (with an average value of $90 \%$ ).

Persistent foaming events (thick, stable, brown to grayish foams) were reported in the CAS WWTP in days 4, 12 to 19, 25,32 , and 33, and mild foaming events (limited and lighter foams) were reported from day 40 to 47 . Regarding the OD WWTP, mild foaming events took place in days 58,69 , and 72.

\section{Sludge characterization}

The microbial aggregate contents (TA/Vol), total filamentous bacteria contents (TL/Vol), and total filament length per total aggregate area (TL/TA) evolution throughout the monitoring period, for both WWTPs, are presented in Fig. 1. The OD WWTP presented TA/Vol contents ranging from 4.0 to $40.3 \mathrm{~mm}^{2} / \mu \mathrm{L}$ (with an average value of $18.5 \mathrm{~mm}^{2} / \mu \mathrm{L}$ ). Regarding the predominant aggregate size class (Fig. 2), there was a clear predominance of mesoflocs in the OD WWTP, ranging from 60.7 to $79.7 \%$ (with an average value of $72.2 \%$ ), throughout the monitoring period (apart from day 16 , which presented a value of $46.1 \%$ ). Conversely, the microfloc area percentage averaged $26.7 \%$ (ranging from 
Table 1 Average, minimum, maximum, and standard deviation values for the MLSS (reactor), and COD and BOD (incoming effluent), in the CAS WWTP and OD WWTP

\begin{tabular}{|c|c|c|c|c|c|c|}
\hline & \multicolumn{3}{|c|}{ CAS WWTP } & \multicolumn{3}{|c|}{ OD WWTP } \\
\hline & $\begin{array}{l}\text { MLSS } \\
(\mathrm{mg} / \mathrm{L})\end{array}$ & $\begin{array}{l}\mathrm{COD} \\
\left(\mathrm{mg} \mathrm{O}_{2} / \mathrm{L}\right)\end{array}$ & $\begin{array}{l}\mathrm{BOD} \\
\left(\mathrm{mg} \mathrm{O}_{2} / \mathrm{L}\right)\end{array}$ & $\begin{array}{l}\text { MLSS } \\
(\mathrm{mg} / \mathrm{L})\end{array}$ & $\begin{array}{l}\mathrm{COD} \\
\left(\mathrm{mg} \mathrm{O}_{2} / \mathrm{L}\right)\end{array}$ & $\begin{array}{l}\mathrm{BOD} \\
\left(\mathrm{mg} \mathrm{O}_{2} / \mathrm{L}\right)\end{array}$ \\
\hline Minimum & 6190 & 696 & 396 & 2700 & 288 & 144 \\
\hline Average & 7877.5 & 886.0 & 448.5 & 3731.4 & 503.1 & 252.7 \\
\hline Maximum & 9500 & 1136 & 543 & 5440 & 896 & 443 \\
\hline Standard deviation & 1366.0 & 184.0 & 65.7 & 920.8 & 242.0 & 113.7 \\
\hline
\end{tabular}

18.5 to $28.4 \%$, apart from day 16 , which presented a value of $51.4 \%$ ), whereas the macrofloc area percentage remained always below $3.2 \%$. With respect to the CAS WWTP, for most of the monitoring period, the TA/ $\mathrm{Vol}$ contents ranged from 30.0 to $133.0 \mathrm{~mm}^{2} / \mu \mathrm{L}$ (with an average value of $58.3 \mathrm{~mm}^{2} / \mu \mathrm{L}$ ). Again mesoflocs predominated, ranging from 51.1 to $71.9 \%$ (with an average value of $63.0 \%$ ) throughout the entire monitoring period. Furthermore, the microfloc area percentage averaged $36.4 \%$ (ranging from 27.8 to $48.9 \%$ ) and the macrofloc area percentage remained always below $2.5 \%$ in the CAS WWTP. Thus, it could be inferred that both WWTP presented a sludge with good morphological characteristics, with respect to the microbial aggregates, given that it was mainly composed by mesoflocs (Amaral 2003; Mesquita et al. 2008, 2011), and that the macrofloc area percentage remained always below the values characterizing viscous bulking phenomena (above $5 \%$ according to Mesquita et al. 2011).

The evolution of the total filamentous bacteria contents (TL/ Vol) and filamentous to aggregated bacteria contents (TL/TA), in both WWTPs, is also presented in Fig. 1. Regarding the OD WWTP, the TL/Vol values ranged from 94.8 to $670.6 \mathrm{~mm} / \mu \mathrm{L}$ (with an average value of $279.6 \mathrm{~mm} / \mu \mathrm{L}$ ), whereas the TL/TA values ranged from 12.8 to $27.7 \mathrm{~mm} / \mathrm{mm}^{2}$ (with an average value of $16.3 \mathrm{~mm} / \mathrm{mm}^{2}$ ). With respect to the CAS WWTP, the $\mathrm{TL} / \mathrm{Vol}$ values ranged from 219.3 to $990.3 \mathrm{~mm} / \mu \mathrm{L}$ (with an average value of $502.1 \mathrm{~mm} / \mu \mathrm{L}$ ) and the TL/TA values ranged from 5.6 to $14.6 \mathrm{~mm} / \mathrm{mm}^{2}$ (with an average value of $9.2 \mathrm{~mm} / \mathrm{mm}^{2}$ ). Previous studies diverge on the maximum TL/ Vol value representing filamentous bulking situations. According to Palm et al. (1980), TL/Vol values larger than $10 \mathrm{~mm} / \mu \mathrm{L}$ may represent already filamentous bulking conditions; however, Mesquita et al. $(2008,2011)$ refer a TL/Vol from 25 to $100 \mathrm{~mm} / \mu \mathrm{L}$, as the bulking limit, depending on the MLSS contents. With respect to the TL/TA parameter, according to Mesquita et al. $(2008,2011)$, the value of $15 \mathrm{~mm} / \mathrm{mm}^{2}$ roughly represents the filamentous bulking limit. Combining both parameters, it can be seen that the CAS WWTP presented TL/TA values below the considered bulking limit, whereas the OD WWTP presented TL/Vol and TL/TA values in the borderline of filamentous bulking.

\section{Filamentous bacteria monitoring}

The main filamentous bacteria organisms present, and monitored, in the studied WWTPs, alongside their wastewater occurrence, are presented in Table 2. The filamentous bacteria community monitoring (see Fig. 3) in the OD WWTP allowed
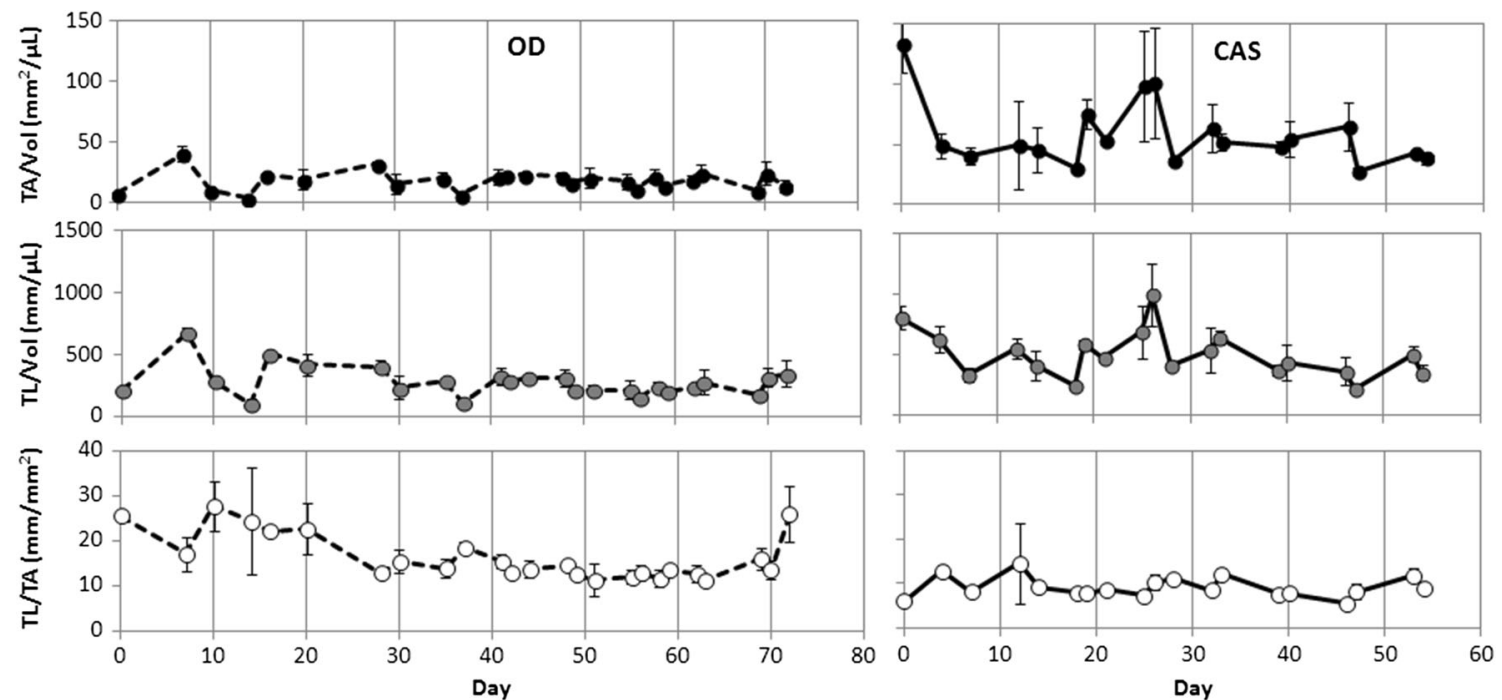

Fig. 1 Evolution of the total area of aggregates per volume (TA/Vol), of the total filament length per volume (TL/Vol), and of the total filament length per total aggregate area (TL/TA) in the CAS WWTP and in the OD WWTP 
Fig. 2 Evolution of the area percentage of micro-, meso-, and macroflocs in the CAS WWTP and in the OD WWTP
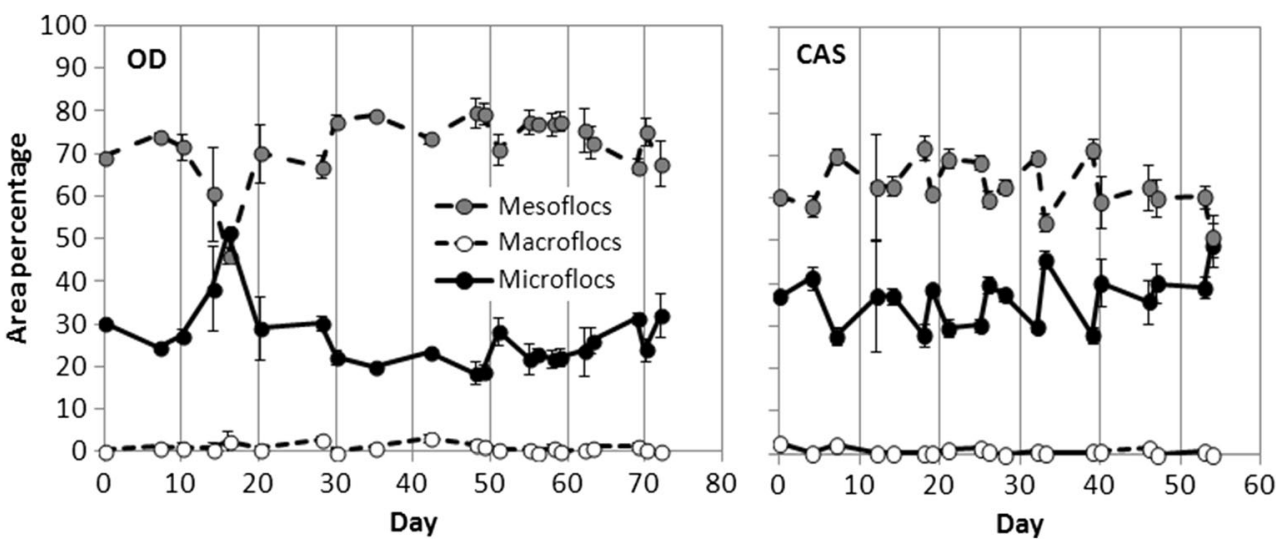

to establish the continuous presence of Thiothrix, Haliscomenobacter hydrossis, and Type 0914/0803, while Type 0092 and Type 0961 were present mostly up until day 42 , and $M$. parvicella appeared solely from day 44 onwards. Furthermore, it should be stressed that no single filamentous bacteria organism was present in large numbers, that is, the individual organism filamentous index rarely surpassed the $100 \mathrm{~mm} / \mu \mathrm{L}$ limit (with a maximum average value for Thiothrix below $60 \mathrm{~mm} / \mu \mathrm{L}$ ). This is in accordance with the fact that no persistent foaming events were reported in the OD WWTP throughout the monitoring period. However, mild foaming events took place at days 58,69, and 72, shortly after the appearance of $M$. parvicella, a known filamentous bacteria capable of producing filamentous foaming, and further corroborated, to a certain degree, by the PCA analysis.

In the CAS WWTP, a predominance of nocardioforms could be found, up until day 40, and the continuous presence of Thiothrix (from day 14 onwards) and Type 0914/0803 for the most part of the monitoring period. Furthermore, up until day 18, Type 0961 was also commonly present and $H$. hydrossis was also present from day 14 to 28 . However, with the exception of the nocardioforms (with an average filamentous index of $190.2 \mathrm{~mm} / \mu \mathrm{L}$ ), and of $M$. parvicella from day 40 onwards, the other filamentous bacteria present rarely occurred in large numbers. A number of foaming events took place on days 4,12 to $19,25,32$, and 33 with the presence of persistent foams in the AS system. These events were, presumably, related with the large numbers of nocardioforms in the above period, which are known to originate foaming events. Also, mild foaming events were reported from day 40 to 47 , presumably related with the occurrence of $M$. parvicella from day 40 onwards. A PCA, alongside cross-correlation analysis and decision trees, was further carried out to verify the presumed relationships.

\section{Protozoa and metazoa monitoring}

The main protozoa and metazoa organisms present, and monitored, in the studied WWTPs, alongside their wastewater occurrence, are presented in Table 2. It could be found (Fig. 4) that testate amoeba were present in the OD WWTP, and mostly predominant up until day 56 . Furthermore, ciliates and flagellates were only noticeable from around day 42 onwards, corresponding to the occurrence of $M$. parvicella. With respect to the metazoa, they were mostly present up until day 48. In the period when mild foaming events took place (starting from day 58), the relative abundance of the testate amoeba started to decrease, the metazoa practically disappeared, and the relative abundance of ciliated protozoa increased.

In the CAS WWTP, testate amoeba, metazoa, and ciliated protozoa dominated in different stages of the monitoring period. Furthermore, within the ciliates, a clear predominance of crawling ciliates was noticed, except from day 46 to 49 (concomitant to mild foaming events) when stalked and freeswimming ciliates dominated. On the other hand, no flagellates were observed during the monitoring period when the persistent foaming events took place and were only noticeable from day 39 onwards, corresponding to the decrease of testate amoeba and the appearance of $M$. parvicella. Overall, no clear predominance of a given set of protozoa class or metazoa could be established throughout the entire monitoring period.

Throughout the OD WWTP monitoring period (with the exception of the last three monitoring days), the SBI (data not shown) presented a value of 5, mainly due to the protozoa scarceness, both in terms of absolute contents and in taxa diversification (overwhelmingly below 5 different organisms). Regarding the CAS WWTP, the SBI value (data not shown) ranged mainly between 7 and 8 , although at day 12 and 14 presented lower values ( 6 and 5 , respectively). It was also found that in the periods presenting persistent foaming events, the SBI presented a maximum value of 7, whereas for most of non-foaming event periods was slightly higher (presenting a value of 8 for most cases).

\section{Statistical analysis}

Principal component analysis (PCA), as reported in Fig. 5, cross-correlation analysis, and decision trees were performed 
Table 2 Main protozoa, metazoa, and filamentous bacteria organisms present in the studied WWTPs and wastewater occurrence

\begin{tabular}{|c|c|}
\hline Organism & Wastewater occurrence \\
\hline \multicolumn{2}{|l|}{ Filamentous bacteria } \\
\hline Type 0961 & High degradability compounds and low $\mathrm{pH}$ \\
\hline Haliscomenobacter hydrossis & $\begin{array}{l}\mathrm{N} \text { or } \mathrm{P} \text { deficiency, high degradability compounds, low } \mathrm{pH} \text {, and low } \\
\text { aeration conditions }\end{array}$ \\
\hline Thiothrix & $\begin{array}{l}\mathrm{N} \text { or P deficiency, high degradability compounds, septic wastewaters } \\
\text { with high organic loads }\end{array}$ \\
\hline Type $021 N$ & $\begin{array}{l}\mathrm{N} \text { or } \mathrm{P} \text { deficiency, high degradability compounds, septic wastewaters } \\
\text { with high organic loads }\end{array}$ \\
\hline Type 0914/0803 & Septic wastewaters with low organic loads and low $\mathrm{pH}$ \\
\hline Type 0092 & Low organic loads and low $\mathrm{pH}$ \\
\hline Microthrix parvicella & Low organic loads, lipidic effluents, low $\mathrm{pH}$, and low aeration conditions \\
\hline Nocardioforms & Low organic loads, lipidic effluents, and low $\mathrm{pH}$ \\
\hline Type 1701 & High organic loads and low aeration conditions \\
\hline \multicolumn{2}{|l|}{ Protozoa } \\
\hline \multicolumn{2}{|l|}{ Small flagellates } \\
\hline Bodo, Cercobodo, etc. & $\begin{array}{l}\text { High organic loads, low aeration conditions, transient phenomena, } \\
\text { low effluent quality }\end{array}$ \\
\hline \multicolumn{2}{|l|}{ Free-swimming ciliates } \\
\hline Uronema & Low aeration conditions \\
\hline Paramecium & Low aeration conditions \\
\hline \multicolumn{2}{|l|}{ Carnivorous ciliates } \\
\hline Coleps hirtus & Low organic loads, aeration \\
\hline Litonotus & Medium loads and transient phenomena \\
\hline \multicolumn{2}{|l|}{ Crawling ciliates } \\
\hline Trithigmostoma & All organic loads, good effluent quality \\
\hline Aspidisca cicada & All organic loads \\
\hline \multicolumn{2}{|l|}{ Stalked ciliates } \\
\hline Vaginicola & Low organic loads, high sludge age, nitrification, aeration \\
\hline Epistylis & Low organic loads, good effluent quality \\
\hline $\begin{array}{l}\text { Vorticella (other than } \\
\text { V. microstoma) }\end{array}$ & All organic loads \\
\hline \multicolumn{2}{|l|}{ Testate amoeba } \\
\hline Euglypha & $\begin{array}{l}\text { Low organic loads, high sludge age, nitrification, aeration, good } \\
\text { effluent quality }\end{array}$ \\
\hline \multicolumn{2}{|l|}{ Metazoa } \\
\hline Monogononta & $\begin{array}{l}\text { Low organic loads, high sludge age, nitrification, aeration, good } \\
\text { effluent quality }\end{array}$ \\
\hline Aeolosoma & $\begin{array}{l}\text { Low organic loads, high sludge age, nitrification, aeration, good } \\
\text { effluent quality }\end{array}$ \\
\hline Gastrotricha & Low organic loads \\
\hline
\end{tabular}

Sources: filamentous bacteria: Duchène and Cotteaux 1998; Eikelboom 2000; Jenkins et al. 2003; protozoa and metazoa: Canler et al. 1999; Madoni 2004, 2011 regarding the filamentous bacteria, protozoa and metazoa, sludge characteristics, and foaming events. It should be noticed that the obtained cross-correlation values regarding the foaming occurrences were affected negatively by the fact these are logical parameters ( 0 or 1) whereas the remaining parameters are discrete or continuous.
As expected, the PCA revealed a strong correlation between the persistent foaming events and the nocardioform presence (Fig. 5a), confirmed, to an extent, by the obtained 0.508 cross-correlation value. In fact, it is well known that nocardioforms are one of the major filamentous bacteria causing foaming events in WWTPs. Although the PCA pointed to the possibility of a correlation between the persistent foaming 

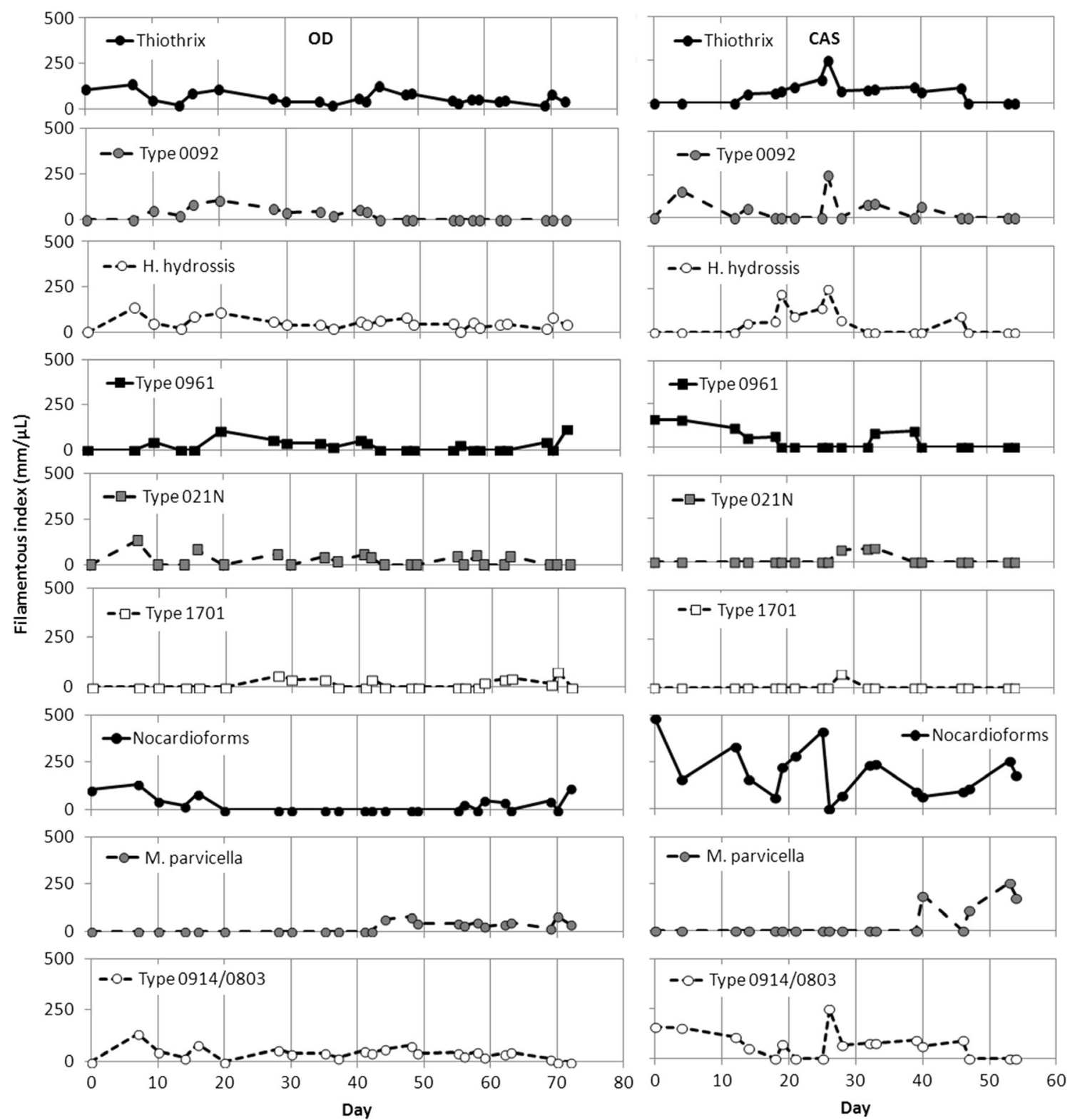

Fig. 3 Filamentous index of the main bacteria present in the CAS WWTP and in the OD WWTP

events and Type 0961, the obtained 0.278 crosscorrelation value failed to confirm this hypothesis. Indeed, no evidence of persistent foaming events caused by Type 0961 is found in the literature. Regarding the mild foaming events, they could be correlated, to a certain degree, with the presence of $M$. parvicella by PCA (Fig. 5a). Although the obtained 0.263 cross-correlation value is far from indicating a strong correlation, it should be stressed that it was the sole positive value obtained between the mild foaming events and the filamentous bacteria present. It should also be stressed that $M$. parvicella, although mainly responsible for filamentous bulking events, is also known to cause foaming events under particular conditions (Duchène and Cotteaux 1998; Eikelboom 2000; Jenkins et al. 2003).
The inner relationships among the filamentous bacteria organisms present in the studied WWTPs were also studied, and two main filamentous bacteria clusters were found. The first, encompassing $H$. hydrossis and Thiothrix, presented a 0.735 cross-correlation value, as expected given that they thrive in similar wastewater characteristics (Table 2). Indeed, analyzing the evolution of $H$. hydrossis and Thiothrix in both WWTPs (Fig. 3), a good agreement between the two could be straightforwardly found. The second cluster related Type 0914/0803 and Type 0092 (also thriving in somewhat similar wastewater characteristics, see Table 2) and was confirmed, to an extent, by the obtained 0.587 cross-correlation value. Although the PCA pointed to the possibility of a correlation between the nocardioforms and Type 0961, the obtained 0.309 crosscorrelation value failed to confirm this hypothesis. 
Fig. 4 Main protozoa and metazoa classes present in the CAS WWTP and in the OD WWTP
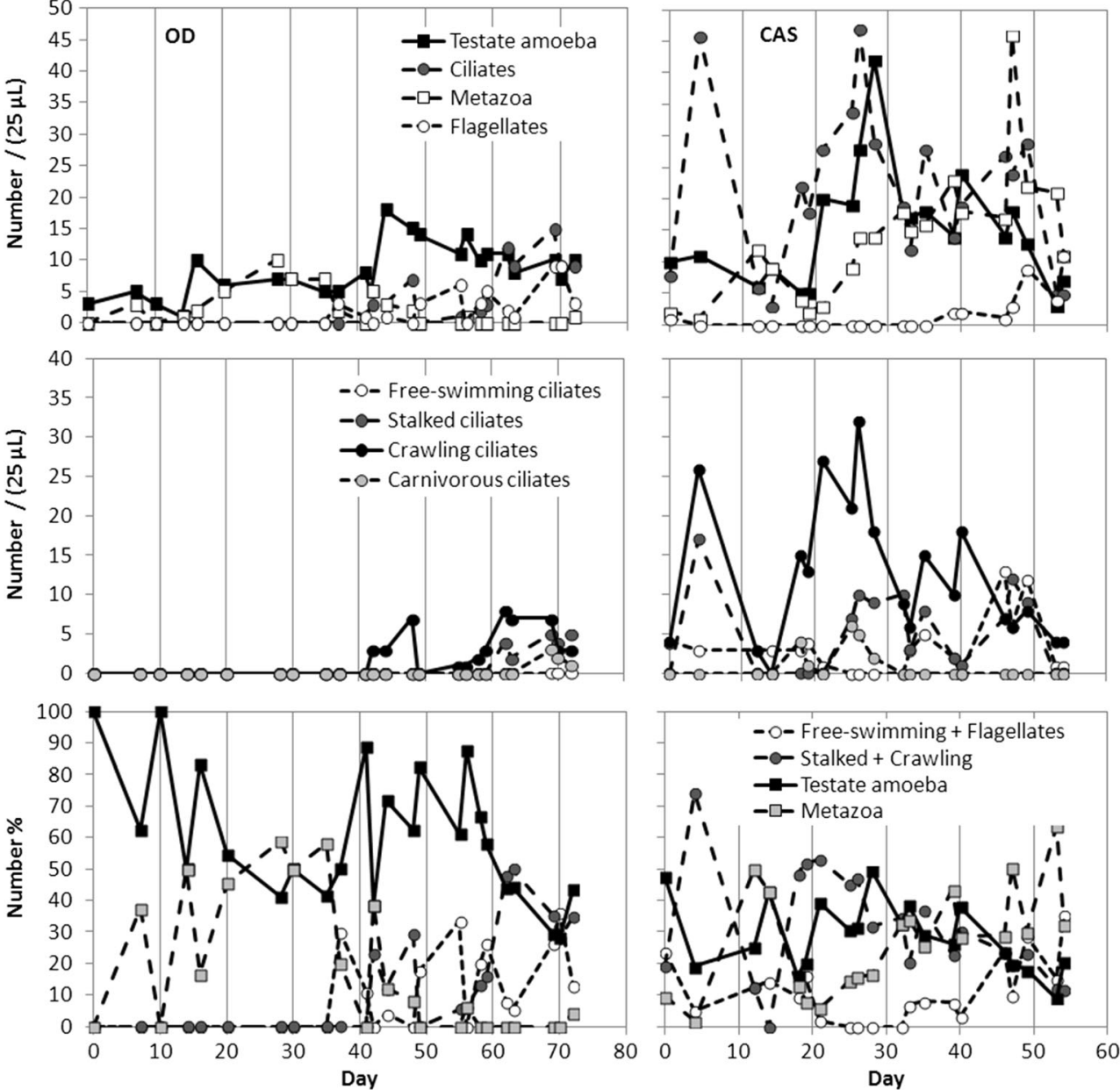

Regarding the sludge characteristics PCA, the overall filamentous bacteria contents seem to be correlated, to a certain degree, with the foaming events (Fig. 5b). From the PCA results, a correlation between the persistent foaming events and the total filamentous bacteria contents (TL/Vol) could be inferred. However, this was not fully confirmed by the obtained cross-correlation value of 0.382 . It should be stressed, though, that the existence of such correlation depends heavily on the relative abundance of the filamentous bacteria responsible for the foaming event in the total filamentous bacteria contents. In fact, this is the main reason why no significant cross-correlation was found between the mild foaming events and the filamentous bacteria contents.

Some other interesting correlations could also be found between the sludge characteristics and the filamentous bacteria organisms present in the studied WWTPs. The TL/Vol was found to be well correlated with the Type 0914/0803 (crosscorrelation value of 0.705 ) and, to an extent, to the nocardioforms (0.615) and Type 0092 (0.529), implying that the changes on these organism contents reflected the overall change of the filamentous bacteria contents. It could also be found that the nocardioforms were positively correlated (cross-correlation value of 0.438 ) with the microfloc contents, suggesting that the biomass deflocculation and the nocardioform increase were, at least in part, correlated to each other.

Regarding the protozoa and metazoa PCA (Fig. 5c), it could be established that the flagellate behavior was quite different from the remaining protozoa and metazoa, as it could be expected. Furthermore, the PCA results and crosscorrelation analysis revealed some interesting correlations between the testate amoeba and the crawling ciliates (cross-correlation value of 0.627$)$, crawling and stalked ciliates (0.591), and even crawling and carnivorous ciliates (0.505). This could also be expected given that the presence of these groups is related to somewhat similar wastewater characteristics, as shown in Table 2 (Madoni 1994, 2011; Canler et al. 1999).

When relating the protozoa and metazoa contents to the foaming events, and regarding mild foams, the flagellates and free-swimming ciliates presented the highest crosscorrelation values ( 0.300 and 0.339 , respectively). Although the obtained values can be considered somewhat low, it should be stressed that these values were still higher than the correlation obtained between the foaming events and $M$. parvicella. 

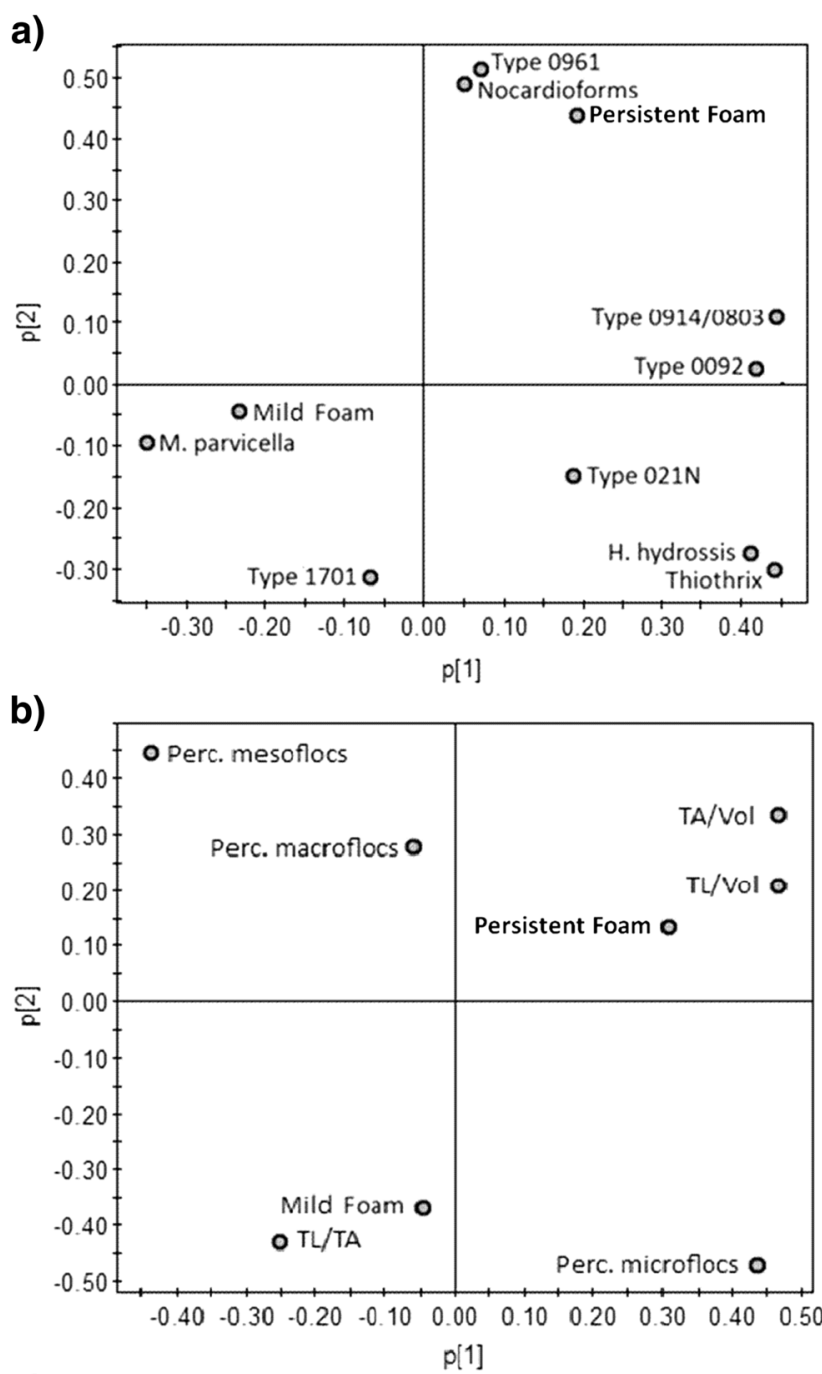

c)

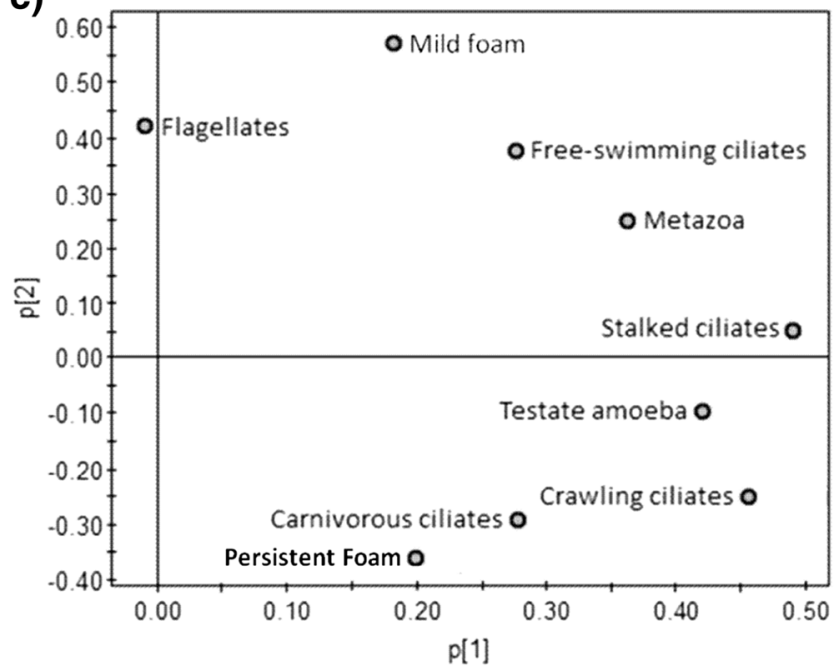

Fig. 5 PCA of a foam occurrences and filamentous bacteria, b sludge characteristics, and $\mathbf{c}$ protozoa and metazoa

Regarding the persistent foaming events, although the carnivorous ciliates were the closest protozoa in PCA, no definitive conclusion could be withdrawn given that this group is frequently found in a wide range of conditions, furthermore taking into account the obtained 0.348 cross-correlation value. It should be stressed though that, when combining the overall foaming events, a cross-correlation value of 0.458 emerged with the free-swimming ciliates, emphasizing the correlation between these organisms and the wastewater characteristics that may lead to foaming events (Table 2). Furthermore, signaling an opposite correlation, a -0.437 cross-correlation value was found between the persistent foaming events and the relative abundance of testate amoeba.

The PCA and regression analysis were also useful for selecting the main parameters studied by decision trees. The first decision tree analysis was then conducted without the filamentous bacteria indices in order to establish if other biota (protozoa and metazoa) or sludge characteristics parameters could be effectively used for foaming event assessment in the studied WWTPs. The obtained results allowed successfully identifying foaming occurrences with an $85.7 \%$ success rate, by the consecutive use of the relative abundance of testate amoeba (below $43.7 \%$ ) and of the microflocs area percentage (above $29.7 \%$ ). Furthermore, the type of foaming event could also be determined, with an accuracy of $75 \%$ for persistent events and of $100 \%$ for mild events, by the later use of the total filamentous bacteria contents- TL/Vol (above and below $489.8 \mathrm{~mm} / \mu \mathrm{L}$, respectively, for persistent and mild events).

When the filamentous bacteria data was introduced, the performed decision trees allowed identifying with success the foaming events with a $92.9 \%$ success rate, by the consecutive use of the relative abundance of testate amoeba (below $43.7 \%$ ) and of the nocardioform filamentous index (above $23.4 \mathrm{~mm} / \mu \mathrm{L}$ ). Again, the type of foaming event could also be determined, with an accuracy of $87.5 \%$ for persistent events and of $100 \%$ for mild events, by the use of the nocardioform filamentous index (above and below $134.4 \mathrm{~mm} / \mu \mathrm{L}$, respectively, for persistent and mild events). These results come as no surprise, given that the nocardioforms are considered to be one of the major causes of persistent events.

Furthermore, the decision trees also allowed establishing some interesting trends in the studied WWTPs. For instance, for free-swimming ciliate contents equal to, or above, $3 /(25 \mu \mathrm{L})$, foaming was also likely to occur. Moreover, persistent foaming events would also be expected to occur when the microfloc area percentage was above $36.9 \%$. On the other hand, mild foaming was likely to occur when the M. parvicella filamentous index was above $48.8 \mathrm{~mm} / \mu \mathrm{L}$. On the contrary, it should be noticed that M. parvicella was absent in all persistent foaming events.

\section{Applicability}

It is true that this methodology requires a non-negligible skilled human effort in monitoring the biota (protozoa, 
metazoa, and filamentous bacteria) contents, alongside the sludge characteristics in a WWTP. On the other hand, the QIA-based determination of sludge characteristics requires as little as 1/2 man-hours, for the sample collection, dilution, sample drying preparation, image acquisition, and (automatic) image processing (the sample drying time would not require any dedicated man-hours). Thus, this makes the QIA-based analysis suitable even for daily monitoring. As for the biota identification, it is expected that a skilled technician would be able to identify the different protozoa, metazoa, and filamentous bacteria present (including the sample collection and staining, if needed) and determine the filamentous index and the SBI, in about one to one and a half man-hours time. It should be noticed, though, that this later analysis may not be required to be performed on a daily basis. In fact, given that a WWTP is working properly, this analysis is suited to be performed on a weekly basis for monitoring purposes. In fact, the QIA-based analysis is intended to promptly identify any change on the sludge structure, whereas the biota monitoring can be used subsequently to identify the main reasons behind the changes and help choosing the best response strategy.

\section{Conclusions}

Two wastewater treatment systems, an oxidation ditch (OD) and a conventional activated sludge (CAS), were monitored throughout a period of 2 and 3 months, respectively, in order to enlighten, from a biological and sludge characteristics point of view, occurring foaming events. The incoming wastewater for both WWTPs was from a domestic nature and presented good biodegradability properties; however, the MLSS were quite higher in the CAS WWTP than in the OD WWTP. COD and BOD levels were also slightly larger in the CAS WWTP. In both WWTPs, average COD and BOD removal efficiencies attained somewhat similar values, above $95 \%$ and around $90 \%$ respectively.

In both WWTPs, the sludge was composed mainly of mesoflocs, with negligible macrofloc contents (responsible for viscous bulking occurrences), which can be considered as presenting good morphological characteristics (with respect to the microbial aggregates). Regarding the total filamentous bacteria contents, they remained below (in the CAS WWTP) or in the borderline (in the OD WWTP) of filamentous bulking phenomena.

The filamentous bacteria monitoring in the OD WWTP allowed establishing that no single filamentous bacteria organism was present in large numbers (surpassing $100 \mathrm{~mm} / \mu \mathrm{L}$ ) throughout the monitoring period. This is in accordance with the absence of persistent foaming events in the OD WWTP. However, the occurrence of $M$. parvicella may have contributed to the reported mild foaming events. Regarding the CAS WWTP, the large presence of nocardioforms can explain the persistent foaming events that periodically took place, as nocardioforms are known to originate foaming events. Also, mild foaming events were also reported, presumably related with the occurrence of M. parvicella.

The protozoa and metazoa monitoring in the OD WWTP allowed determining a shift on the protozoa composition with the onset of $M$. parvicella, towards the occurrence of ciliates and flagellates, and the decrease of the testate amoeba. Similar behavior was observed for the testate amoeba in the CAS WWTP with the occurrence of M. parvicella. Both shifts corresponded also to mild foaming events.

The PCA analysis of the studied WWTPs data allowed correlating, to a certain extent, the occurrence of mild foaming events with the free-swimming ciliates and $M$. parvicella. Moreover, PCA also allowed establishing a correlation between the persistent foaming events and nocardioforms, further confirmed by the cross-correlation analysis. Furthermore, also the testate amoeba relative abundance, microfloc area percentage and total filamentous bacteria contents could be correlated, to a certain degree, with the foaming events. It should be stressed, though, that the later correlation depends heavily on the weight of the filamentous bacteria responsible for the foaming event in the overall filamentous bacteria contents.

Finally, a decision tree analysis was performed on the acquired data for foaming event assessment. It could be found that the combined use of the relative abundance of testate amoeba and nocardioform filamentous index allowed assessing the occurrence of foaming events with a $92.9 \%$ success rate. Furthermore, the type of foaming event could also be determined, with accuracies of $87.5 \%$ for persistent events and of $100 \%$ for mild events. In addition, when no filamentous bacteria indices were used for the foaming assessment, the obtained identification accuracy was of $85.7 \%$ for foaming events and of 75 and $100 \%$, respectively, for persistent and mild events. In this case, the relative abundance of testate amoeba, microfloc area percentage, and TL/Vol were the parameters that made obtaining recognition values possible.

\section{References}

Amaral AL (2003) Image analysis in biotechnological processes: applications to wastewater treatment. PhD Dissertation, Universidade do Minho

Amaral AL, Ferreira EC (2005) Activated sludge monitoring of a wastewater treatment plant using image analysis and partial least squares regression. Anal Chim Acta 544:246-253

APHA, AWWA, WPCF (1998) Standard methods for the examination of water and wastewater. American Public Health Organization, American Water Works Association and Water Environment Federation, Washington D.C

Breiman L, Friedman J, Olshen R, Stone C (1984) Classification and regression trees. Wadsworth, Belmont 
Canler JP, Peret JM, Duchène P, Cotteux E (1999) Aide au diagnostic des stations d'épuration par l'óbservation microscopique dês boues actives. Cemagref Editions, Bordeaux

Comas J, Rodríguez-Roda I, Gernaey K, Rosén C, Jeppsson U, Poch M (2008) Risk assessment modelling of microbiology-related solids separation problems in activated sludge systems. Environ Model Software 23:1250-1261

Costa JC, Mesquita DP, Amaral AL, Alves MM, Ferreira EC (2013) Quantitative image analysis for the characterization of microbial aggregates in biological wastewater treatment: a review. Environ Sci Pollut Res 20:5887-5912

da Motta M, Pons MN, Roche N (2001) Automated monitoring of activated sludge in a pilot plant using image analysis. Water Sci Technol 43(7):91-96

da Motta M, Pons MN, Roche N (2003) Monitoring filamentous bulking in activated sludge systems fed by synthetic or municipal wastewater. Bioprocess Biosyst Eng 25(6):387-393

Dubber D, Gray NF (2009) Enumeration of protozoan ciliates in activated sludge: determination of replicate number using probability. Water Res 43:3443-3452

Duchène P, Cotteaux E (1998) La problématique des disfonctionnements biologiques: bulking et moussage des boues activées. Tribune de l'eau 59(5):59-66

Eikelboom DH (2000) Process control of activated sludge plants by microscopic investigation. IWA Publishing, London

Einax JW, Zwanziger HW, Geiss S (1997) Chemometrics in environmental analysis. VCH Verlagsgesellshaft, Weinheim

Fryer M, Gray NF (2012) Foaming Scum Index (FSI) - a new tool for the assessment and characterisation of biological mediated activated sludge foams. J Environ Manage 110:8-19

Fryer M, O'Flaherty E, Gray NF (2011) Evaluating the measurement of activated sludge foam potential. Water 3(1):424-444

Ganczarczyk JJ (1983) Activated sludge process theory and practice. Marcel Dekker, New York

Ginoris YP, Amaral AL, Nicolau A, Coelho MAZ, Ferreira EC (2007) Recognition of protozoa and metazoa using image analysis tools, discriminant analysis, neural networks and decision trees. Anal Chim Acta 595(1-2):160-169

Grijspeerdt K, Verstraete W (1997) Image analysis to estimate the settleability and concentration of activated sludge. Water Res 31 : 1126-1134

Heard J, Harvey E, Johnson B, Wells J, Angove M (2008) The effect of filamentous bacteria on foam production and stability. Colloid Surface B 63:21-26

Hladikova K, Ruzickova I, Klucova P, Wanner J (2002) An investigation into studying of the activated sludge foaming potential by using physico-chemical parameters. Wat Sci Technol 46:525

Jenkins D, Richard MG, Dagger GT (2003) Manual on the causes and control of activated sludge bulking, foaming, and other separation problems. IWA Publishing, London

Jenné R, Banadda EN, Smets IY, Deurinck J, Van Impe JF (2007) Detection of filamentous bulking problems: developing an image analysis system for sludge composition monitoring. Microsc Microanal 13:36-41

Kocianova E, Foot R, Forster C (1992) Physico-chemical aspects of activated sludge in relation to stable foam formation. Wat Environ $\mathrm{J} 6$ : 342-350

Lemmer H, Lind G, Müller E, Schade M, Ziegelmayer B (2000) Scum in activated sludge plants: impact of non-filamentous and filamentous bacteria. Acta Hydroch Hydrob 28:34-40

Lopez C, Pons MN, Morgenroth E (2005) Evaluation of microscopic techniques (epifluorescence microscopy, CLSM, TPE-LSM) as a basis for the quantitative image analysis of activated sludge. Water Res 39(2-3):456-468
Louvet JN, Giammarino C, Potier O, Pons MN (2010) Adverse effects of erythromycin on the structure and chemistry of activated sludge. Environ Pollut 158(3):688-693

Madoni P (1994) A sludge biotic index (SBI) for the evaluation of the biological performance of activated sludge plant based on the microfauna analysis. Water Res 28:67-75

Madoni P (2004) Applicazione dell' indice biotico del fango (S.B.I.) nel processo di depurazione a fanghi attivi. Università degli Studi di Parma, Parma

Madoni P (2011) Protozoa in wastewater treatment processes: a minireview. Italian J Zool 78(1):3-11

Mesquita DP, Amaral AL, Ferreira EC (2011) Identifying different types of bulking in an activated sludge system through quantitative image analysis. Chemosphere 85:643-652

Mesquita DP, Dias O, Amaral AL, Ferreira EC (2008) Relationship between sludge volume index and biomass within activated sludge systems. Proceedings of the XVII Congresso Brasileiro de Engenharia Química, Recife, 7 p. CD-ROM.

Mesquita DP, Dias O, Elias RAV, Amaral AL, Ferreira EC (2010) Dilution and magnification effects on image analysis applications in activated sludge characterization. Microsc Microanal 16:561-568

Nakajima J, Mishima I (2005) Measurement of foam quality of activated sludge in MBR process. Acta Hydroch Hydrob 33:232-239

Nicolau A, Dias N, Mota M, Lima N (2001) Trends in the use of protozoa in the assessment of wastewater treatment. Res Microbiol 152:621630

Nicolau A, Neto MM, Santos L, Fernandes V, Mota M (2015) PROTOFILWW: two year-sampling of protozoa, little metazoa and filamentous bacteria in 37 Portuguese wastewater treatment plants. J Biotechnol 208(Suppl):S18

Palm JC, Jenkins D, Parker DS (1980) Relationship between organic loading, dissolved-oxygen concentration and sludge settleability in the completely mixed activated sludge process. J Water Poll Control Fed 52:2484-2506

Pandolfi D, Pons MN, da Motta M (2007) Characterization of PHB storage in activated sludge extended filamentous bacteria by automated colour image analysis. Biotechnol Lett 29(8):1263-1269

Pons MN, Milferstedt K, Morgenroth E (2009) Biofilm monitoring on rotating discs by image analysis. Biotechnol Bioeng 103(1):105116

Richard M (1991) Activated sludge microbiology. The Water Pollution Control Federation, Virginia

Santos LA, Ferreira V, Neto MM, Pereira MA, Mota M, Nicolau A (2015) Study of 16 Portuguese activated sludge systems based on filamentous bacteria populations and their relationships with environmental parameters. Appl Microbiol Biotechnol 99(12):5307-5316

Singh KP, Malik A, Mohan D, Sinha D, Singh VK (2005) Chemometric data analysis of pollutants in wastewater - a case study. Anal Chim Acta 532:15-25

Stalder T, Alrhmoun M, Louvet JN, Casellas M, Maftah C, Carrion C, Pons MN, Pahl O, Ploy MC, Dagot C (2013) Dynamic assessment of the floc morphology, bacterial diversity, and integron content of an activated sludge reactor processing hospital effluent. Environ Sci Technol 47:7909-7917

Tchobanoglous G, Burton FL, Stensel HD (2003) Metcalf \& Eddy wastewater engineering treatment disposal and reuse. McGraw Hill, New York

Tharrault Y, Mourot G, Ragot J (2009) WWTP diagnosis based on robust principal component analysis. Proceedings of the 7th IFAC Symposium on Fault Detection, Supervision and Safety of Technical Processes 1342-1347.

Torregrossa M, Viviani G, Vinci V (2005) Foaming estimation tests in activated sludge systems. Acta Hydroch Hydrob 33:240-246 